\title{
Proteomic Analysis of Human Breast Cancer Cells Treated with Monascus-Fermented Red Mold Rice Extracts
}

\author{
Chu-I Lee ${ }^{1}$, Shu-Ling Hsieh², Chih-Chung Wu ${ }^{3}$, Chun-Lin Lee ${ }^{4}$, Yueh-Ping Chang ${ }^{5}$, Jyh-Jye Wang ${ }^{5, *}$ \\ ${ }^{1}$ Department of Medical Laboratory Science and Biotechnology, Fooyin University, Jinxue Rd., Daliao Dist., Kaohsiung, Taiwan \\ ${ }^{2}$ Department of Seafood Sciences, National Kaohsiung Marine University, Haijhuan Rd., Nanzih Dist., Kaohsiung City, Taiwan \\ ${ }^{3}$ Department of Nutrition and Health Sciences, Chang Jung Christian University, No.1,Changda Rd., Gueiren District, Tainan City , \\ Taiwan \\ ${ }^{4}$ Department of Life Science, National Taitung University, Sec.1 Chunghua Rd., Taitung, Taiwan \\ ${ }^{5}$ Department of Nutrition and Health Science, Fooyin University, Jinxue Rd., Daliao Dist., Kaohsiung, Taiwan \\ *Corresponding author: ft054@fy.edu.tw
}

Received April 30, 2015; Revised May 18, 2015; Accepted May 27, 2015

\begin{abstract}
Monascus-fermented red mold rice (RMR) extracts have recently been proved to possess anticancer activities, but the anticancer effect of breast cancer cells treated with RMR is not yet well understood. In an effort to identify proteins that may be involved in RMR-induced breast cancer cell death, we employed proteomic analysis coupled with LC-nanoESI-MS/MS on MCF-7 cells exposed to two RMR extracts, ethyl acetate extract (EAE) and ethanol extract (EE). Sixupregulated proteins were identified in EAE-induced MCF-7 cells, including glyceraldehyde-3-phosphate dehydrogenase, pyruvate dehydrogenase E1 component, heat shock 27 kDa protein 1, cathepsin D, protein disulphideisomerase A3, and prohibitin. The upregulated expression of other 4 proteins was seen in EE-induced MCF-7 cells, including alloalbuminvenezia, annexin A5, endoplasmic reticulum protein 29 isoform 1 precursor, and cellular retinoic acid binding protein 2. The same two down-regulated proteins were identified on cells after treatment with both extracts, dermcidin preproprotein and poly(rC) binding protein 1 . These proteins have been implicated in proapoptotic regulation, stress modulation, tumor suppression, and survival factor activity. These analysescould provide valuable information for further exploration of RMR as a promising chemopreventive agent against breast cancer.
\end{abstract}

\section{Keywords: Breast cancer cells, Monascuspurpureus, Proteomics, Red mold riceextracts}

Cite This Article: Chu-I Lee, Shu-Ling Hsieh, Chih-Chung Wu, Chun-Lin Lee, Yueh-Ping Chang, and JyhJye Wang, "Proteomic Analysis of Human Breast Cancer Cells Treated with Monascus-Fermented Red Mold Rice Extracts." Journal of Food and Nutrition Research, vol. 3, no. 5 (2015): 325-329. doi: 10.12691/jfnr-3-5-6.

\section{Introduction}

Breast cancer is the most common type of cancer and the leading cause of cancer-related mortality in women [1]. Considerable efforts are being made to identify new agents as health food supplements for effective chemopreventive treatment of breast cancer.

Monascus-fermented red mold rice (RMR) is a traditional food and folk medicine used by Asian people and has recently become a popular health supplement. Recently, we demonstrated that ethanol extract (EE) and ethyl acetate extract (EAE) from fermented RMR (Monascuspurpureus NTU 803) exhibited direct cytotoxic and proapoptotic effects on MCF-7 human breast cancer cells. Several bioactive compositions such as monacolin K, total phenolic, and flavonoids were found in RMR EE and $\mathrm{EAE}$, and the antioxidative ability and antiproliferative activity of these active ingredients in RMR extracts have also been implicated in breast cancer prevention [2].
However, RMR extracts exhibit multiple anticancer activities, and the mechanisms of action are not completely understood [3]. This inspires us to further investigate the altered protein profiles associated with RMR-induced antiproliferation in breast cancer cells.

Proteomics technologies have made possible a broad survey of all the functional categories of proteins, revealing their differential expression patterns in pathological tissue from various diseases as well as response to treatment [4]. Proteomic analysis coupled with liquid chromatography-nanoelectrospray ionization tandem mass spectrometry (LC-nanoESI-MS/MS) is a well-established technique for peptide sequencing analysis [5]. The objective of this work was to search for potential targets of RMR treatment in MCF-7 breast cancer cells through a proteomic approach using two-dimensional gel electrophoresis and LC-nanoESI-MS/MS for protein identification. This allows us to characterize the putative protein biomarkers indicative of RMR-induced MCF-7 cell death to elucidate the pathophysiological mechanisms of breast cancer chemoprevention. 


\section{Materials and Methods}

\subsection{Chemicals and Reagents}

Dulbecco's modified Eagle's medium (DMEM) and fetal bovine serum (FBS) were purchased from Gibco (Grand Island, NY). The 2-DE reagents were from Amersham Biosciences (Uppsala, Sweden). Modified trypsin (sequence-grade) was obtained from Promega (Madison, WI). Dimethyl sulfoxide (DMSO) and other chemicals not specified above were purchased from Sigma (St. Louis, MO).

\subsection{Microorganism and Red Mold Rice (RMR)Preparation}

Monascuspurpureus NTU 803, a monacolin Kproducing fungal strain isolated from fermented longgrain rice, was identified as $M$. purpureus and deposited at the Bioresource Collection and Research Center in Taiwan (BCRC 930147). For RMR preparation, $500 \mathrm{~g}$ of long grain rice was soaked in distilled water for $8 \mathrm{~h}$. After that, excess water was removed with a sieve. Then, the soaked rice was autoclaved for $20 \mathrm{~min}$ at $121^{\circ} \mathrm{C}$. After being sterilized, the substrate was inoculated with a $5 \%$ (v/w) spore suspension of $M$. purpureus NTU 803, and the inoculated substrate was cultivated at $30^{\circ} \mathrm{C}$ for 10 days [2]. The resulted dried rice was then mechanically crushed into powder and was called RMR.

\subsection{Cell Culture}

Human breast adenocarcinoma cells (MCF-7; BCRC 60436) were maintained at $37^{\circ} \mathrm{C}$ in a humidified atmosphere containing $5 \% \mathrm{CO}_{2}$ in DMEM, supplemented with $10 \% \mathrm{FBS}, 100 \mathrm{IU} / \mathrm{mL}$ penicillin, and $100 \mu \mathrm{g} / \mathrm{mL}$ streptomycin.

\subsection{Preparation of RMR Extracts}

Preparation of RMR extracts was performed according to a previously described method [2]. After fermentation, the crushed and dried RMR (300 g) wasextracted by $95 \%$ ethanol $(1,500 \mathrm{~mL})$ at $37^{\circ} \mathrm{C}$ for $18 \mathrm{~h}$ to yield the $\mathrm{EE}$ and then dried under vacuum. Another $300 \mathrm{~g}$ of RMR was extracted with ethyl acetate at $37^{\circ} \mathrm{C}$ for $18 \mathrm{~h}$ to yield the EAE. Both extracts were soluble in dimethyl sulfoxide (DMSO). In this study, the yield of dried ethyl acetate extract (EAE) and ethanol extract (EE) from RMR was 6.86 and $7.01 \%$ of the original weight, respectively.

\subsection{Sample Preparation and Two- Dimensional Electrophoresis (2-DE)}

The cells were trypsinized and diluted with lysis buffer. Isoelectrofocusing was performed using an EttanIPGphor II system (Amersham Biosciences). Ready-to-use ImmobilineDryStrips (pH 3-10 NL) were rehydrated for 12 hours at room temperature in rehydration buffer. Cell lysate $(100 \mu \mathrm{g})$ was mixed with rehydration buffer containing $100 \mathrm{mMDeStreak}$ reagent instead of $20 \mathrm{mM}$ DTT. After cup-loading by the manufacturer's protocol, protein focusing was conducted for a total of $17000 \mathrm{Vh}$. The IPG strips were equilibrated for $15 \mathrm{~min}$ in equilibration buffer, followed by the same solution containing 2.5\% (w/v) iodoacetamide instead of DTT for 15 min. The second dimension was performed by $12 \%$ SDS polyacrylamide gels with a constant voltage of $65 \mathrm{~V}$ for 0.5 hours and then $120 \mathrm{~V}$ for 14 hours. The separated gels were fixed, washed and visualized by silver staining and then the spots were analyzed using the Image Master 2D Platinum system.

\subsection{In-gel Digestion}

An in-gel digestion protocol was adapted to the previously described method[6]. Briefly, silver stained protein spots were excised, destained, washed and dehydrated in acetonitrile for $20 \mathrm{~min}$. The solution was then aspirated and gel pieces were brought to complete dryness. Gel pieces were rehydrated with a freshly prepared solution of sequence-grade modified trypsin (20 $\mathrm{ng} / \mu \mathrm{L}$ in a $25 \mathrm{mM}$ ammonium bicarbonate buffer) at $37^{\circ} \mathrm{C}$ for 16 hours. The tryptic peptides were extracted with $50 \%$ acetonitrile containing $5 \%$ formic acid by sonication. The extracted solutions were evaporated to dryness in a SpeedVac and then redissolved in $10 \mu \mathrm{L}$ $0.1 \%$ formic acid.

\subsection{Protein Identification by Liquid Chromatography-nanoelectrosprayIonization Tandem Mass Spectrometry (LC-nanoESI- MS/MS)}

Peptides separated from the capillary column were directed to the nanospray source by a $20 \mu$ mi.d. and 90 $\mu$ mo.d. fused-silica capillary. A voltage of $3.2 \mathrm{kV}$ was applied to the nanosource. The mass spectrometer was operated in positive ion mode with a cone voltage of $80 \mathrm{~V}$ and a source temperature of $80^{\circ} \mathrm{C}$. The TOF analyzer was set in the V-mode. MS-MS spectra were acquired in a data-dependent acquisition mode in which the two multiple-charged (+2 and +3 ) peaks with the three most abundant ions were selected for collision-induced dissociation. The parent ion was excluded if the same molecular weight ion was detected within 200 second. MS (precursor scan) to MS-MS (fragment scan) and MS-MS to MS scan were automatic mode. The scan range of precursor and fragment ions was $\mathrm{m} / \mathrm{z}$ 400-3000 and m/z 100-3000, respectively. During the auto scans, collision energies were set at 10 and $30 \mathrm{~V}$ and argon was used as the collision gas. MS-MS spectra obtained for each of the parent ions were processed by MassLynx 4.0 software (Manchester, UK) to get the corresponding peak lists. For database searching, the peak list files (pkl files) were uploaded to the MASCOT (http://www.matrixscience.com) search engine to obtain corresponding protein identity. Variable modifications such as oxidation of methionine and carbamidomethylation of cysteine were selected.

\section{Results and Discussion}

During the recovery of neoplastic cells to healthy cells, distinct changes may occur at the protein level such as altered expression, differential protein modification, and changes in specific activity. In this study, we evaluated cellular responses to RMR extract treatments using cancer proteomics studies. A previous toxicology study focused 
on the effect of one specific component in red mold rice (RMR) [7]; however, various bioactive compositions of RMR may be attributed to synergy between a number of secondary metabolites (citrinin, monacolin K, dimerumic acid, flavonoids, and total phenols) and other compounds. Thus we preferred to use whole extracts of RMR rather than its constituents for our study.

According to our previous investigation, two samples, ethyl acetate extract (EAE) and ethanol extract (EE), were obtained by extraction of the total ethyl acetate fraction and total ethanol fraction of $M$. purpureus fermented RMR. MCF-7 cells were treated with DMSO (0.1\%), EAE(IC $\left.{ }_{50}, 107 \pm 9.3 \mu \mathrm{g} / \mathrm{mL}\right)$, or EE $\left(\mathrm{IC}_{50}, 85 \pm 6.5 \mu \mathrm{g} / \mathrm{mL}\right)$ for $24 \mathrm{~h}$ [2]. To further identify the molecular players involved in RMR-induced apoptosis in breast cancer cells, proteins were extracted directly from MCF-7 cells and resolved by two-dimensional electrophoresis (2-DE)gels using IPG (linear) to separate the extracted proteins. As shown in Figure 1, silver staining visualized more than 600 protein spots on the 2-DE gels after individual EE and EAE treatment. In this investigation, we found that although EAE and EE treatments shared a similar proteomic fingerprint, each RMR extract treatment exhibited a different protein expression profile. After analyzing the proteome maps, these peptides were excised from each differentially expressed protein spot by in-gel tryptic digestion and proteins were identified using LCnanoESI-MS/MS.
A

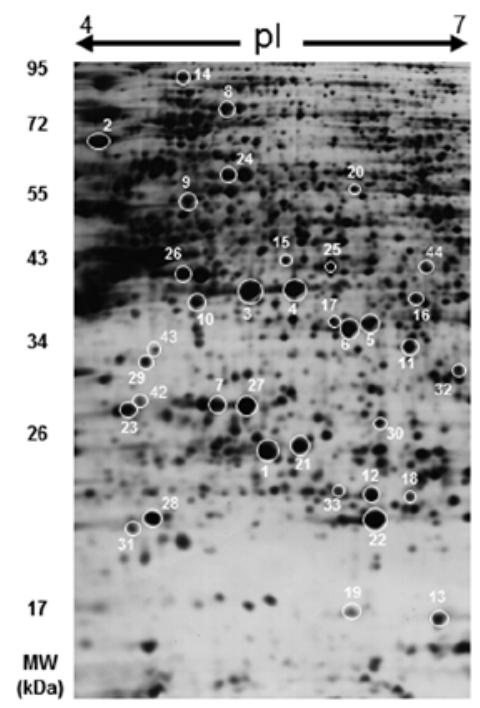

EAE-treated
B

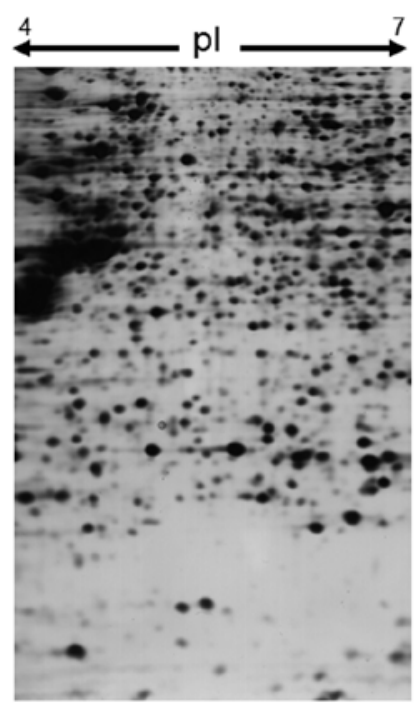

Control
C

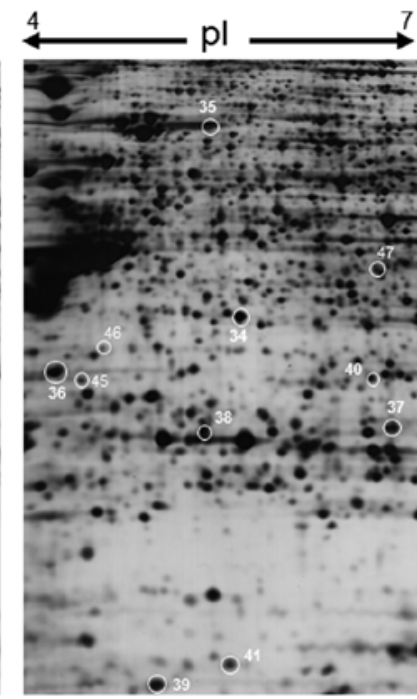

EE-treated

Figure 1. Representative two-dimensional electrophoresis gels maps. MCF-7 cells were treated with(A)EAE (IC $50,107 \pm 9.3 \mu \mathrm{g} / \mathrm{mL})$, $(\mathrm{B}) 0.1 \%$ DMSO(control), and(C) EE ( $\left.\mathrm{IC}_{50}, 85 \pm 6.5 \mu \mathrm{g} / \mathrm{mL}\right)$. The protein $(100 \mu \mathrm{g})$ was applied to pH $3-10$ linear IPG strips, using $10 \%$ vertical linear gradient SDS-PAGE as the second dimension. The gel was visualized by silver staining. The differentially expressed proteins are marked with a circle and numbered. Details of the proteins are given in Table 1, Table 2 and Table 3

Around 33 protein spots (spot 1 to 33) were revealed to have increased expressions when EAE-treated cells and control cells were compared on the 2-DE gel according to image analysis. Six upregulated proteins were identified in the EAE group, including glyceraldehyde-3-phosphate dehydrogenase, pyruvate dehydrogenase E1 component, heat shock $27 \mathrm{kDa}$ protein 1, cathepsin $\mathrm{D}$, protein disulphideisomerase A3, and prohibitin, which were associated with anticancer properties through EAEinduced MCF-7 cell death (Table 1).

Table 1. List of differentially upregulated proteins isolated from 2-DE gel of MCF-7 cells after treatment with EAE and identified by LCnanoESI-MS/MS analysis

\begin{tabular}{|c|c|c|c|c|c|c|c|}
\hline Spot number ${ }^{\mathrm{a}}$ & Protein name & $M w^{\mathrm{b}}$ & $p I^{\mathrm{b}}$ & $\begin{array}{l}\text { Peptides } \\
\text { matched }\end{array}$ & $\begin{array}{l}\text { Sequence } \\
\text { coverage (\%) }\end{array}$ & $\begin{array}{l}\text { MOWSE } \\
\text { Score }^{\mathrm{c}}\end{array}$ & Function \\
\hline 3 & $\begin{array}{l}\text { glyceraldehyde-3-phosphate } \\
\text { dehydrogenase }\end{array}$ & 35648 & 5.78 & 9 & 9 & 194 & $\begin{array}{l}\text { Glycolysis; } \\
\text { mediator }\end{array}$ \\
\hline 21 & heat shock $27 \mathrm{kDa}$ protein 1 & 22768 & 5.98 & 4 & 14 & 119 & Stress-mediated chaperonage \\
\hline 23 & cathepsin D & 26283 & 5.14 & 3 & 15 & 113 & Proapoptotic mediator \\
\hline 27 & Prohibitin & 29786 & 5.57 & 2 & 6 & 85 & Tumor suppress protein \\
\hline
\end{tabular}

${ }^{\mathrm{a}}$ The spot number is as indicated in Figure 1.

${ }^{\mathrm{b}}$ The molecular weight $(M w)$ and isoelectric point $(p I)$ were calculated values based on the identified proteins.

${ }^{\mathrm{c}}$ The confidence scores are based on search results from MS-MS data analysis using the Mascot search engine.

The glyceraldehyde-3-phosphate dehydrogenase (GAPDH) protein was previously only thought to be involved in glycolysis to break down glucose for energy and carbon molecules. In addition to this long established metabolic function, GAPDH has recently been implicated in several non-metabolic processes, including transcription activation and initiation of apoptosis [8]. Our finding of the effects of EAE on the overexpression of GAPDH is 
consistent with the role of GAPDH in proapoptotic activities. In this work, the pyruvate dehydrogenase E1 component showed upregulation in the EAE treated cells. Consistent with data obtained in the present study, pyruvate dehydrogenase E1 is has antiproliferation activity in human cancer cells [9].

Heat shock proteins, which are stress-mediated chaperones, appeared overexpressed and implicated in cancer cell proliferation and death. Heat shock $27 \mathrm{kDa}$ protein 1 (Hsp 27-1) is a family member of the small heat shock proteins, which is increased in various human cancers and exhibits cytoprotective activity that affects tumorigenesis and the susceptibility of tumors to cancer therapy [10]. Hsp 27-1 was another protein found to be strongly upregulated in EAE-treated MCF-7 cells. The upregulation of Hsp 27-1 protein in MCF-7 cells may account for its relative cytoprotective activity in EAEinduced apoptosis.

Although cathepsin D, a lysosomal aspartic protease, has been used as a breast cancer tumor marker, it is also a key mediator of induced apoptosis [11]. Since cathepsin D is involved in the regulation of cell proliferation, it is reasonable that overexpression of cathepsin $\mathrm{D}$ would be related to EAE-induced antiproliferation in MCF-7 cells. Similarly, recent evidence shows that cytotoxic agents can increase the expression of endoplasmic reticulum-resident proteins such as protein disulphideisomerase A3 and A4 [12]. In our study EAE induced the expression of protein disulphideisomerase A3 in MCF-7 cells. Further investigation to confirm the key molecular events associated with increases in the expression of ER chaperones in EAE treated MCF-7 cells will shed more light on the mechanisms of action of RMR. Molecular overexpression of proteins encoded by the oncogenes and decreased expression of tumor suppressor proteins are known to be responsible for carcinogenesis. Prohibitin is characterized as a potential tumor suppressor protein, and a regulator of cell cycle progression and in apoptosis [13]. Prohibitinupregulationwas induced in MCF-7 cells after EAE exposure in this study, suggesting that prohibitin is indeed a potential tumor suppressor protein acting in apoptosis.

Around 8 protein spots (spot 34 to 41 ) were revealed to have increased expressions in EE-treated cells compared to control cells on the 2-DE gel. Of these identified proteins, 4 upregulated proteins, including alloalbuminvenezia, annexin A5, endoplasmic reticulum protein 29 isoform 1 precursor, and cellular retinoic acid binding protein 2 were associated with anticancer properties in EE-induced MCF7 cell death (Table 2).

Table 2. List of differentially upregulated proteins isolated from 2-DE gel of MCF-7 cells after treatment with EE and identified by LCnanoESI-MS/MS analysis

\begin{tabular}{|c|c|c|c|c|c|c|c|}
\hline Spot number ${ }^{a}$ & Protein name & $M w^{\mathrm{b}}$ & $p I^{\mathrm{b}}$ & $\begin{array}{l}\text { Peptides } \\
\text { matched }\end{array}$ & $\begin{array}{l}\text { Sequence } \\
\text { coverage (\%) }\end{array}$ & $\begin{array}{l}\text { MOWSE } \\
\text { Score }^{\mathrm{c}} \\
\end{array}$ & Function \\
\hline 35 & alloalbuminvenezia & 69181 & 5.99 & 2 & 3 & 54 & Tumor suppress protein \\
\hline 36 & annexin 5 & 35914 & 4.94 & 8 & 16 & 230 & $\begin{array}{l}\text { Calcium-binding protein; } \\
\text { Antiproliferation }\end{array}$ \\
\hline 38 & $\begin{array}{l}\text { endoplasmic reticulum protein } \\
29 \text { isoform } 1 \text { precursor }\end{array}$ & 28975 & 6.77 & 4 & 19 & 231 & $\begin{array}{l}\text { Endoplasmic reticulum } \\
\text { stress }\end{array}$ \\
\hline 39 & $\begin{array}{l}\text { cellular retinoic acid binding } \\
\text { protein } 2\end{array}$ & 15527 & 5.23 & 4 & 23 & 106 & Proapoptosis \\
\hline
\end{tabular}

${ }^{\mathrm{a}}$ The spot number is as indicated in Figure 1.

${ }^{\mathrm{b}}$ The molecular weight $(M w)$ and isoelectric point $(p I)$ were calculated values based on the identified proteins.

'The confidence scores are based on search results from MS-MS data analysis using the Mascot search engine.

Downregulated expression of alloalbuminveneziawas previously reported in lung cancer specimens by proteomic analysis [14]. Increased expression of alloalbuminveneziaafter exposure to EE in MCF-7 cells was seen in the present investigation, suggesting that the functional role of alloalbuminvenezia might include anticancer properties. Annexin V has been characterized as a calcium-binding protein which exhibited a dual activity. Although the upregulation of annexin A5 promotes progression of various cancers, it is negatively correlated with tumorigenesis in some other cancer cells [15]. Our data indicated a possible link between the inhibition of cell proliferation and upregulated expression of annexin A5 after EE treatment.

Endoplasmic reticulum protein 29 isoform 1 precursor (ERP29-1) is known to be an ER stress-activated protein. Increased expression of ERP29-1 could result in transcriptional activation of genes with tumor suppressive function and lead to cell growth arrest [16]. The increase of ERP29-1 in EE-treated MCF-7 cells perhaps indicates the induction of ER stress relating to cell antiproliferation by RMR. This result also implies that not only apoptosis but also autophagy could contribute to RMR-induced cell death. Further investigations are required to find the precise role of ERP29-1 in the activation of ER stress signaling pathways regulating EE-mediated MCF-7 autophagy. The anticarcinogenic activities of retinoic acid
(RA) are believed to be mediated by the cellular retinoic acid-binding protein-II (CRABP-II), a RA-binding protein. More recent evidence indicated that growth inhibition by RA arrests an early cell cycle followed by induction of apoptosis in MCF-7 cells [17]. Moreover, overexpression of CRABP-II upregulated the expression of Apaf1 and triggered caspase 7 and caspase 9 cleavage in MCF-7 cells [18]. The data obtained in the present investigation are consistent with the proapoptoticrole of CRABP-II.

In the tested groups, protein spots of decreased expressions in EAE- and EE-treated cells on the 2-DE gel were 3 (spot 42 to 44) and 3 (spot 45 to 47), respectively. Another interesting observation was that the same two proteins downregulated in both extract groups were dermcidinpreproprotein and poly(rC) binding protein 1 (Table 3). The expression of dermcidin was characterized originally as an antimicrobial peptide [19]. In particular, dermcidin has been described as a survival factor in breast cancer [20]. The poly(rC) binding protein 1 has been implicated transcription modulation. Recently, downregulatedpoly(rC) binding protein 1 was demonstrated to be associated with apoptosis in lung cancer cells [21]. Consistent with the above results, our experimental results showed that both $\mathrm{EE}$ and $\mathrm{EAE}$ induced downregulation of these two cancer-related proteins, indicating a further anticancer effect of RMR extracts on MCF-7 cells. 
Table 3. List of differentially downregulated proteins isolated from 2-DE gel of MCF-7 cells after treatment with EAE and EE and identified by LC-nanoESI-MS/MS analysis

\begin{tabular}{|c|c|c|c|c|c|c|c|}
\hline Spot number ${ }^{\mathrm{a}}$ & Protein name & $M w^{\mathrm{b}}$ & $p I^{\mathrm{b}}$ & $\begin{array}{l}\text { Peptides } \\
\text { matched }\end{array}$ & $\begin{array}{l}\text { Sequence } \\
\text { coverage (\%) }\end{array}$ & $\begin{array}{l}\text { MOWSE } \\
\text { Score }^{\mathrm{c}}\end{array}$ & Function \\
\hline 43 (EAE); 46 (EE) & dermcidinpreproprotein & 11277 & 6.08 & 1 & 10 & 61 & Survival factor \\
\hline 44 (EAE); 47 (EE) & poly(rC) binding protein 1 & 37502 & 6.66 & 3 & 8 & 106 & Transcription \\
\hline
\end{tabular}

${ }^{\mathrm{a}}$ The spot number is as indicated in Figure 1.

${ }^{\mathrm{b}}$ The molecular weight $(M w)$ and isoelectric point $(p I)$ were calculated values based on the identified proteins.

'The confidence scores are based on search results from MS-MS data analysis using the Mascot search engine.

\section{Conclusions}

This is the first report providing a proteomic profile of the response of MCF-7 cells to RMR extracts. These differentially expressed proteins explained the cytotoxicity of RMR against human breast cancer MCF-7 cells, and their identification may explain the multiple anticancer activities of RMR. The potency of RMR induction of breast cancer cell death might be based on its ability to regulate several key players in apoptosis, stress, tumor suppression and survival mechanisms. More work is needed to elucidate the complicated signal cascades related to these altered protein expressions. The experimental results of this study may provide novel investigational targets for further studies of the molecular mechanisms of RMR for breast cancer prevention or therapy.

\section{Acknowledgements}

The authors thank the National Science Council (NSC 99-2313-13-242-001-MY3)for the financial support of this work. The authors are also thankful to Ms. Carol Perng for her assistance in wording improvement of the manuscript.

\section{Conflicts of Interest}

All authors declare no conflicts of interest.

\section{References}

[1] Castrellon A.B., Gluck S., "Chemoprevention of breast cancer”,Expert review of anticancer therapy, 8, 443-52, 2008.

[2] Lee C.I., Lee C.L., Hwang J.F., Lee Y.H., Wang J.J., “Monascusfermented red mold rice exhibits cytotoxic effect and induces apoptosis on human breast cancer cells",Applied microbiology and biotechnolog, 97, 1269-78, 2013.

[3] Shi Y.C., Pan T.M., "Beneficial effects of Monascuspurpureus NTU 568-fermented products: a review”,Applied microbiology and biotechnolog, 90, 1207-17, 2011.

[4] Umar A., Kang H., Timmermans A.M., Look M.P., Meijer-van Gelder M.E., den Bakker M.A., Jaitly N., Martens J.W., Luider T.M., Foekens J.A., Pasa-Tolić L., "Identification of a putative protein profile associated with tamoxifen therapy resistance in breast cancer”,Molecular \& cellular proteomics, 8, 1278-94, 2009.

[5] Bicudo R.C., Bicudo T.C., Forato L.A., Titato G.M., Colnago L.A., Lanças F.M., "Identification of non-zein proteins in BR473 maize protein bodies by LC-nanoESI-MS/MS”, Journal of separation science, 32,3579-84, 2009.

[6] Chen Y.Y., Lin S.Y., Yeh Y.Y., Hsiao H.H., Wu C.Y., Chen S.T., Wang A.H., "A modified protein precipitation procedure for efficient removal of albumin from serum”,Electrophoresis, 26, 2117-27, 2005.

[7] Lin W.Y., Song C.Y., Pan T.M., "Proteomic analysis of Caco-2 cells treated with monacolin K”,Journal of agricultural and food chemistry, 54, 6192-200, 2006.
[8] Hara M.R., Agrawal N., Kim S.F., Cascio M.B., Fujimuro M., Ozeki Y., Takahashi M., Cheah J.H., Tankou S.K., Hester L.D., Ferris C.D., Hayward S.D., Snyder S.H., Sawa A., "S-nitrosylated GAPDH initiates apoptotic cell death by nuclear translocation following Siah1 binding”, Nature cell biology, 7, 665-74, 2005.

[9] Glushakova L.G., Lisankie M.J., Eruslanov E.B., Ojano-Dirain C., Zolotukhin I., Liu C., Srivastava A., Stacpoole P.W., “AAV3mediated transfer and expression of the pyruvate dehydrogenase E1 alpha subunit gene causes metabolic remodeling and apoptosis of human liver cancer cells",Molecular genetics and metabolism, 98, 289-99, 2009.

[10] Parcellier A., Schmitt E., Brunet M., Hammann A., Solary E., Garrido C., "Small heat shock proteins Hsp27 and alpha Bcrystallin: cytoprotective and oncogenic functions”, Antioxidants \& redox signaling,7, 404-13, 2005.

[11] Liaudet-Coopman E., Beaujouin M., Derocq D., Garcia M., Glondu-Lassis M., Laurent-Matha V., Prébois C., Rochefort H., Vignon F., "Cathepsin D: newly discovered functions of a longstanding aspartic protease in cancer and apoptosis”, Cancer Letters,237, 167-79, 2006.

[12] Agarwal N.K., Mueller G.A., Mueller C., Streich J.H., Asif A.R., Dihazi H., "Expression proteomics of acute promyelocyticleukaemia cells treated with methotrexate", Biochimica et biophysicaacta, 1804, 918-28, 2010.

[13] Joshi B., Ko D., Ordonez-Ercan D., Chellappan S.P., “A putative coiled-coil domain of prohibitin is sufficient to repress E2F1mediated transcription and induce apoptosis”, Biochemical and biophysical research communications, 312, 459-66, 2003.

[14] Li L.S., Kim H., Rhee H., Kim S.H., Shin D.H., Chung K.Y., Park K.S., Paik Y.K., Chang J., Kim H., "Proteomic analysis distinguishes basaloid carcinoma as a distinct subtype of nonsmall cell lung carcinoma”,Proteomics, 4, 3394-400, 2004.

[15] Peng B., Guo C., Guan H., Liu S., Sun M.Z., “Annexin A5 as a potential marker in tumors”,Clinicachimicaacta, 427, 42-8, 2013.

[16] Bambang I.F., Xu S., Zhou J., Salto-Tellez M., Sethi S.K., Zhang D., "Overexpression of endoplasmic reticulum protein 29 regulates mesenchymal-epithelial transition and suppresses xenograft tumor growth of invasive breast cancer cells”,Laboratory investigation, 89,1229-42, 2009.

[17] Donato L.J., Suh J.H., Noy N., "Suppression of mammary carcinoma cell growth by retinoic acid: the cell cycle control gene Btg2 is a direct target for retinoic acid receptor signaling”, Cancer research,67, 609-15, 2007.

[18] Donato L.J., Noy N., "Suppression of mammary carcinoma growth by retinoic acid: proapoptotic genes are targets for retinoic acid receptor and cellular retinoic acid-binding protein II signaling”, Cancer research,65, 8193-9, 2005.

[19] Schittek B., Hipfel R., Sauer B., Bauer J., Kalbacher H., Stevanovic S., Schirle M., Schroeder K., Blin N., Meier F., Rassner G., Garbe C., "Dermcidin: a novel human antibiotic peptide secreted by sweat glands”, Nature immunology, 2, 1133-7, 2001.

[20] Porter D., Weremowicz S., Chin K., Seth P., Keshaviah A., LahtiDomenici J., Bae Y.K., Monitto C.L., Merlos-Suarez A., Chan J., Hulette C.M., Richardson A., Morton C.C., Marks J., Duyao M., Hruban R., Gabrielson E., Gelman R., Polyak K., “A neural survival factor is a candidate oncogene in breast cancer",Proceedings of the National Academy of Sciences of the United States of America, 100, 10931-36, 2003.

[21] Pyo J.S., Roh S.H., Kim D.K., Lee J.G., Lee Y.Y., Hong S.S., Kwon S.W., Park J.H., "Anti-cancer effect of Betulin on a human lung cancer cell line: a pharmacoproteomic approach using $2 \mathrm{D}$ SDS PAGE coupled with nano-HPLC tandem Mass Spectrometry”, Plantamedica, 75,127-31, 2009. 